\title{
O coordenador pedagógico e a formação continuada no programa Ler e Escrever
}

\author{
Camila dos Santos Almeida \\ Elvira Cristina Martins Tassoni \\ Pontifícia Universidade Católica de Campinas
}

\section{Resumo}

Este artigo resulta de pesquisa que investigou o processo de formação de professores proposto pelo programa Ler e Escrever do Estado de São Paulo. 0 material empírico contou com análise documental, observações de momentos formativos, em uma Diretoria de Ensino e em uma escola, além de entrevista semiestruturada com a professora coordenadora. Os resultados apontaram que a formação privilegia vivências e repasse de práticas, num processo de convencimento estabelecido em uma relação de poder. Apesar de se constatar um fortalecimento da função do professor coordenador, o programa vincula a importância do trabalho desse profissional à melhoria do desempenho dos alunos nas avaliações em larga escala.

Palavras-chave: Coordenador pedagógico. Formação continuada. Política de formação de professores. 


\section{The teacher coordinator and continued education in the Ler e Escrever Program}

This article results from research that investigated the process of teacher education proposed by the Ler e Escrever Program the state of São Paulo. The empirical material included documentary analysis, observations of educational moments at a board of education and school, as well as a semi-structured interview with the teacher coordinator. The results showed that the education favors experiences and the transference of practices, in a process of convincing, established in a power relationship. Although it was noticed that the function of teacher coordinator is strengthened, the program links the importance of this professional to improvement of student performance in large-scale tests.

Keywords: Teacher coordinator. Continued education. Teacher training policy.

\section{El coordinador docente y la formación continuada en el Programa Ler e Escrever}

Este artículo es el resultado de la investigación que investigó el proceso de la formación del profesorado propuesto por programa Ler e Escrever, del Estado de São Paulo. El material empírico consistió en el análisis documental, observaciones de momentos formativos en un consejo de educación y la escuela, así como la entrevista semiestructurada con el coordinador docente. Los resultados mostraron que la formación favorece la transferencia de experiencias y prácticas en un proceso convincente establecido en una relación de poder. Aunque parece que el fortalecimiento de la función de coordinador docente, el programa vincula a la importancia de esta mejora profesional del desempeño de los estudiantes en las evaluaciones a gran escala.

Palabras-clave: Pedagógico coordinador. Formación continuado. Política de formación del professorado. 


\section{Introdução}

Este artigo é resultado de pesquisa que teve por objetivo problematizar a realidade da formação continuada de professores no Estado de São Paulo, mais especificamente no âmbito da proposta do programa Ler e Escrever. Teve por foco principal a formação dos professores coordenadores e a sua atuação como formadores de professores da rede.

Inicialmente, trazemos apontamentos introdutórios sobre o programa. Em seguida, pressupostos teóricos a respeito da formação continuada de professores, para, na sequência, destacar a figura do professor coordenador como formador na escola. Depois, apresentamos parte dos resultados da pesquisa, trazendo a proposta de formação continuada de professores do programa Ler e Escrever.

Para a construção do material empírico, utilizamos o conceito de Gatti (2002, p. 43) em que "método não é algo abstrato. Método é ato vivo, que se revela nas nossas ações, na nossa organização do trabalho investigativo, na maneira como olhamos as coisas do mundo." Buscando compreender o processo de formação de professores no programa Ler e Escrever, com foco na figura do professor coordenador, apresentamos a organização metodológica, ou seja, a forma como foram "olhadas as coisas do mundo", como descreve Gatti e, neste caso, a formação de professores no programa Ler e Escrever. A pesquisa envolveu o espaço de formação dos professores coordenadores de núcleo pedagógico - PCNPs, a Diretoria de Ensino de Jacareí e o espaço de formação dos professores - uma escola estadual da mesma cidade. Dessa forma, foi possível observar momentos formativos no interior da escola, sob a responsabilidade da professora coordenadora, bem como momentos de formação de PCNPs, responsáveis pela formação dos professores coordenadores. A pesquisa contou ainda com entrevista semiestruturada com a professora coordenadora da escola selecionada, distribuição de questionário para o grupo de professores dessa escola e análise de documentos oficiais, disponibilizados on-line pelo Estado.

É previsto pelo art. 67 da Lei de Diretrizes e Bases da Educação Nacional, Lei no 9.394, de 1996 (Brasil, 1996), que os sistemas de ensino deverão promover a valorização dos profissionais da educação, assegurando-lhes, nos termos dos estatutos e dos planos de carreira do magistério, aperfeiçoamento profissional contínuo. Segundo Gatti (2008), existe uma diversidade de iniciativas em torno da formação continuada no País, expressa nos sucessivos programas de formação continuada promovidos pela esfera pública.

O contexto histórico que situa a criação do programa Ler e Escrever teve influência das ideias apresentadas pelo programa Letra e Vida. Este programa, 
idealizado em 1999 e com início de aplicação no ano 2001, foi oferecido aos professores dos anos iniciais do ensino fundamental, com o objetivo de formar professores alfabetizadores em uma concepção diversa daquela que embasava a educação tradicional, elaborando uma proposta influenciada pela teoria de Emília Ferreiro e Ana Teberosky - pesquisadoras que elaboraram uma teoria explicativa, de base construtivista, sobre o desenvolvimento da escrita na criança, descrevendo quatro diferentes níveis, os quais revelam as hipóteses elaboradas pelas crianças, visando à compreensão do funcionamento do sistema alfabético.

Em 2005, os insatisfatórios resultados demonstrados pelo Sistema de Avaliação de Rendimento do Estado de São Paulo - SARESP levaram os órgãos reguladores da educação estadual a implantar o programa Ler e Escrever, por meio da Resolução SE nº 86, de 19 de dezembro de 2007 (São Paulo, 2007a), com o objetivo de alfabetizar todos os alunos com até o $3^{\circ}$ ano do ensino fundamental da rede estadual de ensino, ou seja, até os oito anos de idade, além de contemplar propostas a fim de recuperar a aprendizagem da leitura e da escrita dos alunos do $4^{\circ}$ e $5^{\circ}$ ano.

Diferentemente do programa Letra e Vida, o programa Ler e Escrever ampliou as frentes de atuação, realizando ações para além das propostas de formação de professores. Contou com a elaboração e a distribuição de material didático - para os alunos e para o professor - e de materiais complementares: livros de literatura e paradidáticos, enciclopédias e outros materiais pedagógicos, como letras móveis, globos terrestres e calculadoras. Foi implantado como uma política pública estadual, tendo como referência a experiência do programa nas escolas municipais da cidade de São Paulo, em 2006 (programa Ler e Escrever, prioridade na escola municipal), além da experiência adquirida com o programa Letra e Vida. Em uma primeira fase de implantação, em 2007, o Ler e Escrever foi levado às escolas estaduais da cidade de São Paulo. Em 2008, estendeu-se à região metropolitana, para afinal, em 2009, ser implantado na rede escolar estadual, em sua totalidade - interior e litoral.

A Secretaria de Educação do Estado de São Paulo - SEESP deixou sob responsabilidade da Coordenadoria de Normas Pedagógicas - CENP, da Fundação de Desenvolvimento da Educação - FDE e da Coordenadoria de Ensino da Região Metropolitana da Grande São Paulo - COGESP a função de elaborar a proposta do programa em seus diferentes âmbitos, inclusive no da formação pedagógica. O planejamento da formação tem início, portanto, nos órgãos vinculados à SEESP que realizam a formação dos professores coordenadores de núcleo pedagógico - PCNPs, profissionais responsáveis pela organização da formação no âmbito das diretorias de ensino - DE, envolvendo os professores 
coordenadores - PCs. Os PCs são profissionais das diversas escolas que aderiram ao programa. 0 último âmbito de formação acontece no interior de cada escola, em reuniões pedagógicas que envolvem os PCs e os professores dos anos iniciais do ensino fundamental.

Ao instituir o programa Ler e Escrever, a SEESP altera, por meio da Resolução SE n 88 e n 89, de 19 de dezembro de 2007 (São Paulo, 2007b, 2007c), as funções e a nomenclatura do coordenador pedagógico. 0 coordenador pedagógico passa a se chamar professor coordenador e torna-se o responsável pelo aperfeiçoamento da prática do seu grupo de professores. A ele cabe a tarefa de apoiar os professores regentes na complexa ação pedagógica de garantir a aprendizagem da leitura e da escrita a todos os alunos, até o final do $3^{\circ}$ ano do ensino fundamental. Também torna-se responsável pela criação de condições institucionais adequadas para mudanças em sala de aula, recuperando a dimensão pedagógica da gestão. A figura do professor coordenador surge, então, como necessidade imperativa no processo de formação continuada nas escolas.

\section{Perspectivas para a formação continuada no lócus escolar}

Partimos da teoria de Vigotski (1995), segundo a qual o desenvolvimento cultural do sujeito só pode ser compreendido em um processo vivo de luta, pois o ser humano está em um constante processo de formação e, por isso, o desenvolvimento é permanente. Desta forma, a arena de lutas acontece, também, durante a formação do educador, e não dizemos aqui somente a formação inicial, mas a que se dá durante todo o seu percurso profissional. Este aspecto é bastante relevante à formação de professores uma vez que, muitas vezes, ela é entendida como um processo harmonioso, natural e tranquilo. Assim, os sujeitos que fazem a escola se colocam em um processo constante de desenvolvimento, num cenário intenso de tensões e contradições. Pensar o desenvolvimento cultural nessa perspectiva nos leva a considerar que as relações que se estabelecem por meio do trabalho são fundamentais para tal desenvolvimento. Segundo Duarte, baseando-se em Vigotski,

o indivíduo se forma apropriando-se dos resultados da história social e objetivandose no interior dessa história, ou seja, sua formação se realiza por meio da relação entre objetivação e apropriação. Essa relação se efetiva sempre no interior de relações concretas com outros indivíduos, que atuam como mediadores entre ele e o mundo humano, o mundo da atividade humana objetivada. A formação do indivíduo é, portanto, sempre um processo educativo, mesmo quando a educação se realiza 
de forma espontânea, isto é, quando não há a relação consciente com o processo educativo que está se efetivando no interior de uma determinada prática social. (Duarte, 2001, p. 167)

A citação acima nos mostra que não só os instrumentos são mediadores do desenvolvimento, mas os sujeitos também se apresentam como atores deste processo, na medida em que se relacionam. A formação, portanto, é um processo contínuo, mediado, possível de acontecer no ambiente escolar.

Ao compreendermos a escola em uma relação dialética com a sociedade e pensarmos que atualmente esta produz cada vez mais saberes, com cada vez mais rapidez, os agentes do processo educativo encontram-se no palco de uma cena viva, cheia de movimento, no que se refere às necessidades formativas. A formação continuada tem se configurado uma realidade necessária à prática pedagógica.

Placco e Silva (2009) destacam que a formação docente é antiga e ao mesmo tempo atual. Antiga, pois em toda a nossa história tem sido questionada a maneira como são formados nossos educadores. Atual porque, nos últimos anos, a formação do professor tem se apresentado como ponto nodal das reflexões sobre qualidade de ensino, dadas as exigências culturais e tecnológicas da sociedade.

Embora seja uma expressão tão falada e supostamente de tão fácil compreensão, a formação continuada de professores não se apresenta como um conceito muito claro, sobretudo porque abarca também todas as iniciativas de formação realizadas após a formação inicial. Abordaremos aqui a formação continuada no lócus escolar, pensando na escola como um espaço originário de formação. É na escola que se podem oportunizar momentos de reflexão direta sobre os educandos, sobre novas possibilidades de ação na troca de experiências e, especialmente, sobre a aprendizagem do professor.

Considerando a escola como um espaço originário de formação, passaremos à análise de como autores de referência na área da formação de professores refletem sobre esta questão.

Para Schön (1992, p. 88), a questão de "o que significa tentar formar um professor para que ele se torne mais capaz de reflectir na e sobre a sua prática”, implica um tipo de formação baseada no aprender-fazendo, com um tutor que envolve o grupo em um diálogo de palavras e desempenhos: "o desempenho do aluno transmite informações muito mais fiável que suas próprias palavras" (Schön, 1992, p.89). 0 autor indica que na produção do aluno deve ser perceptível a orientação do tutor. A imitação - em especial a do tutor - é tida como válida e relevante ao processo. 0 que Schön descreve pode ser vivenciado por professor e aluno na sala de aula, como também por professor e seu tutor - que tem 
papel de formador -, em um processo de interação que produz conhecimento da prática e da reflexão da prática.

Nóvoa (1992, p. 25) defende a práxis como lugar de produção de saber e como espaço para uma atenção especial às vidas dos professores. "A teoria fornece-nos indicadores e grelhas de leitura, mas o que o adulto retém como saber de referência está ligado à sua experiência e à sua identidade." Defende, igualmente, a partilha de experiências e saberes, no sentido de consolidar um espaço de formação mútua, em que cada profissional desempenha tanto a função de formador, como de formado. Na perspectiva de Nóvoa, o diálogo entre os profissionais é fundamental nos espaços formativos. 0 autor afirma, ainda, que este é o único processo capaz de conduzir a uma transformação de perspectiva e a uma produção de saberes reflexivos e pertinentes dos próprios professores.

Concluindo, Nóvoa sintetiza as ideias da seguinte maneira:

Toda a formação encerra um projeto de acção. E de trans-formação. E não há projecto sem opções. As minhas passam pela valorização das pessoas e dos grupos que têm lutado pela inovação no interior das escolas e do sistema educativo. Outras passarão pela tentativa de impor novos dispositivos de controle e de enquadramento. Os desafios da formação de professores (e da profissão docente) jogam-se nesse confronto. (Nóvoa, 1992, p. 31)

Observamos, então, que tanto as ideias de Schön quanto as de Nóvoa em relação à formação pautam-se pelo pressuposto do professor reflexivo, trazendo como central em tal processo os diferentes movimentos de reflexão feitos pelos professores nas situações concretas do dia a dia e a partir delas, tendo como marca o coletivo - as interações entre pares. No entanto, Pimenta (2002, p. 22) problematiza o modelo de formação proposto, por meio dos seguintes apontamentos: "que tipo de reflexão tem sido realizada pelos professores? As reflexões incorporam um processo de consciência das implicações sociais, econômicas e políticas da atividade de ensinar? Que condições têm os professores para refletir?"

Na contramão da perspectiva de Schön, Pimenta (2002, p. 24) considera que o saber docente não é formado apenas da prática, "sendo também nutrido pelas teorias da educação", enunciando uma centralidade da teoria na formação dos professores uma vez que "dota os sujeitos de variados pontos de vista para uma ação contextualizada, oferecendo perspectivas de análise para que os professores compreendam os contextos históricos, sociais, culturais, organizacionais e de si próprios como profissionais." A autora defende o papel da teoria como "possibilidade para a superação do practicismo". (Pimenta, 
Arce (2000) agudiza a crítica aos aportes do professor reflexivo, detectando a influência desta formação nos documentos políticos normatizadores da educação, especialmente da educação infantil - objeto de estudo da autora -, mas que podem abranger os demais níveis de ensino. A autora caracteriza o discurso do professor reflexivo fortalecido nas políticas neoliberais com o trabalho docente cada vez mais impulsionado - rebaixado - à categoria do individualismo, elevado ao paroxismo, passando a imperar um "salve-se quem puder", em que se instaura uma nova fórmula exploratória do trabalhador.

Em contrapartida, Nóvoa (2009), em suas discussões sobre uma formação de professores construída dentro da profissão, traz o princípio de responsabilidade social como um dos itens importantes a serem considerados no processo formativo. 0 autor sugere um "novo contrato entre professores e a sociedade", apontando um sentido para retomar a "credibilidade" social da escola que foi perdida com o tempo. 0 caminho sugerido é a realização de maiores "exposições públicas, "comunicando para fora da escola", ou seja, reforçando sua "presença pública”. Nóvoa (2009) alerta que tal exposição pode trazer vulnerabilidade tanto para as escolas como para os professores, mas afirma que essa seria a condição essencial para a evolução e transformação da escola.

Para que a formação de professores seja marcada pelo princípio de responsabilidade social, a escola precisa se fortalecer em sua função, que é ensinar, tornar possível a apropriação dos conhecimentos produzidos e acumulados socialmente. Recuperar o espaço social da escola se faz necessário; entretanto, pensamos também na necessidade de o processo formativo no interior da escola refletir sobre a prática e também refletir sobre a sua função social.

0 processo formativo, até aqui problematizado no campo das ideias e teorias, recebe como figura principal o professor coordenador, no programa Ler e Escrever. Para compreender a função deste profissional, também no campo das ideias e teorias, trazemos agora uma síntese dos estudos realizados que fizeram parte da pesquisa que apresentamos.

\section{0 coordenador pedagógico: uma função em construção}

Inicialmente o coordenador pedagógico recebia a nomenclatura de supervisor. Na pesquisa de Placco, Almeida e Souza (2011), é chamado de coordenador pedagógico; em outras pesquisas, aparece apenas coordenador e, mais recentemente, no Estado de São Paulo, a nomenclatura usada é professor 
coordenador. Historicamente, foram se apresentando diferentes formas de nomear o professor coordenador, que, consequentemente, carregavam novas maneiras de compreender o papel desse profissional. 0 que podemos perceber nos estudos é um movimento de mudança e de busca de definição da função, que se revela também pelas diferentes formas de nomeação.

Tendo sua função criada a princípio para inspecionar o trabalho dos professores e auxiliar a direção, a função até hoje se encontra em um processo de construção no que se refere às suas atribuições. Acreditamos que o volume das produções que vêm sendo realizadas no campo acadêmico voltadas ao coordenador pedagógico, seja no sentido de desvelar essa função e construir a identidade desse profissional, se justifica para que de fato não se mantenha a afirmação de Roman (2001, p. 74): “o professor coordenador pedagógico não tem nada de professor, nada de coordenador, muito menos de pedagógico".

A formação continuada vem sendo defendida na literatura como papel essencial do coordenador pedagógico. Nas leituras que realizamos percebemos que Christov (2009) posicionam-se na perspectiva do professor reflexivo. Outros autores como Franco (2009), Guimarães e Villela (2009), Bruno e Christov (2009) não esclarecem a perspectiva desta formação, mas fazem considerações sobre como deve se efetivar a prática do coordenador em relação ao professor iniciante, ao início do ano letivo, e como organizar as reuniões.

Defendemos, aqui, a formação no interior da escola como um espaço formal de educação continuada que proponha situações sistematizadas de ensino e aprendizagem, que contribuam para o professor compreender seu papel político na sociedade, ampliar seus conhecimentos - científicos, de mundo, de estratégias - de forma crítica, utilizando esta criticidade para selecionar os conteúdos para seu grupo de alunos e sabendo que aluno pretende-se formar, para além do jargão "formar cidadãos críticos". Um local em que o professor sinta-se à vontade - à vontade no sentido de não oprimido, de respeitado, de possuir também voz - em um espaço de troca e construção de conhecimentos, sentindo, na figura do professor coordenador, um mestre e um parceiro, um mediador no processo de desenvolvimento profissional. Enfim, um espaço assim como a sala de aula, que tenha as especificidades e complexidades que demanda a formação de um professor, assim como as especificidades de cada turma.

\section{O programa Ler e Escrever e a sua proposta de formação de professores}

Para o levantamento do material empírico foram utilizados alguns procedimentos: análise dos documentos que orientam o programa Ler e Escrever 
e a função do professor coordenador; observações de diferentes momentos de formação -formação de professor coordenador de núcleo pedagógico (PCNP) e formação de professores em aula de trabalho pedagógico coletivo (ATPC) na escola -; e entrevista semiestruturada com a PC. Por se tratar de investigação de um processo, que envolve diversos sujeitos, o aprofundamento maior foi sobre o trabalho da professora coordenadora, que é o foco de nossa pesquisa.

O programa Ler e Escrever busca a mudança de paradigma em relação à alfabetização, por meio de novas práticas pedagógicas. Para atuar nesta mudança, intitulou, como já explicitado, o professor coordenador como responsável pela política de melhoria da qualidade de ensino, cujo acompanhamento se faz por meio dos índices de desempenho dos alunos nas avaliações em larga escala. Assim, uma das responsabilidades do professor coordenador é promover o aperfeiçoamento da prática pedagógica do seu grupo de professores. No discurso dos documentos oficiais relacionados ao programa Ler e Escrever, a prática é apontada com maior frequência, secundarizando-se a teoria no processo formativo que o professor coordenador protagoniza.

Conforme já detalhado, para exercer essa função, o PC recebe uma formação na Diretoria de Ensino, organizada pelos professores coordenadores de núcleo pedagógico (PCNP), que por sua vez receberam uma formação do grupo de formadores da Coordenadoria de Estudos e Normas Pedagógicas (CENP).

0 material empírico nos possibilitou problematizar, inicialmente, as relações de poder envolvendo os diferentes profissionais da escola, pautadas tanto pela estabilidade de cada um deles no cargo, quanto pelo nível de conhecimento demonstrado sobre o programa Ler e Escrever. Vejamos: o professor coordenador é um professor concursado que faz parte do quadro funcional da Secretaria Estadual de Educação e, para chegar à referida função, precisou passar por um processo seletivo interno da Diretoria de Ensino. Este envolve a elaboração de um projeto contemplando as metas para a melhoria da qualidade de ensino da escola em que o professor pretende atuar e a aprovação em uma entrevista realizada por supervisores e pelo diretor da escola. Para se manter no cargo, o professor coordenador também depende da avaliação desses mesmos profissionais sobre o seu trabalho. Esses aspectos revelam a condicionalidade da função do professor coordenador em relação aos supervisores e ao diretor da escola.

Os momentos de observação e entrevista nos permitiram compreender como se dá a organização dos sujeitos que fazem parte do processo formativo do programa. Sintetizamos esta organização no esquema a seguir: 
Figura I: Organização dos sujeitos no processo formativo do programa Ler e Escrever

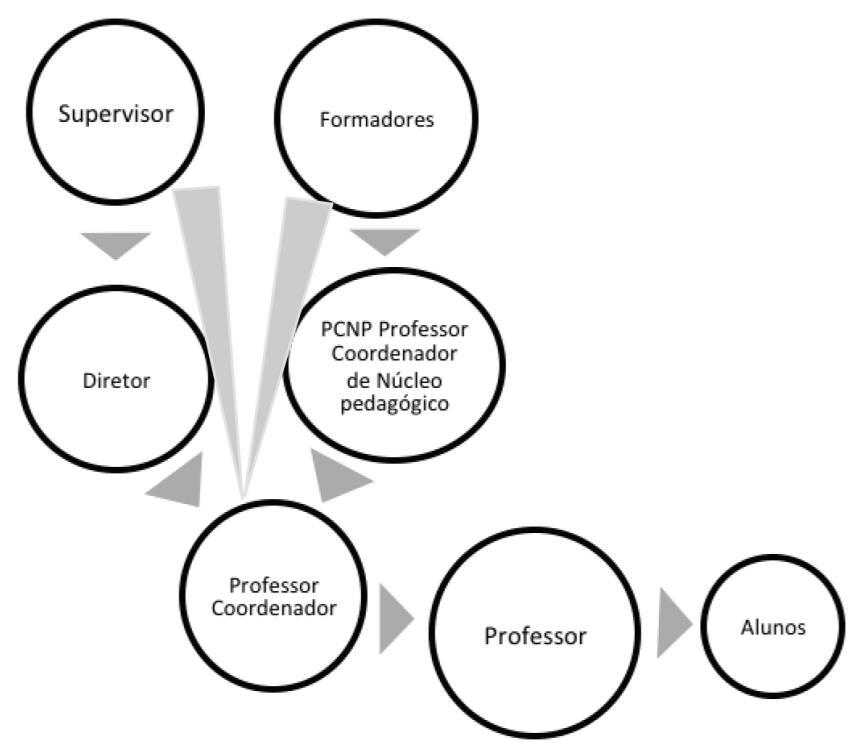

Fonte: Elaborado pelas pesquisadoras.

Observamos a convergência de forças sobre o professor coordenador, a saber: em relação à escola, temos o supervisor e o diretor e, no que se refere à proposta de formação do programa Ler e Escrever, temos os formadores (no âmbito dos órgãos vinculados à Secretaria da Educação do Estado de São Paulo) e os PCNP (no âmbito das diretorias de ensino). Desde a análise do discurso dos documentos oficiais, temos identificado tamanhas expectativas geradas sobre a função do PC. Neste esquema, é possível notar o quanto as ações de diferentes sujeitos estão ligadas ao trabalho do PC, ao mesmo tempo que ele exerce responsabilidade pelo trabalho pedagógico do professor e pela aprendizagem dos alunos. Supervisores, diretores, formadores e PCNP estabelecem relação direta com o trabalho do professor coordenador. Todos passam prescrições diretas ao PC com a intenção de que essas prescrições alterem a realidade das práticas de sala de aula e, dessa forma, promovam a chamada melhoria da qualidade. Um aspecto observado e importante de ser ressaltado é que o discurso dos sujeitos aponta para uma relação de poder existente nesse quadro. Esta relação se dá por meio da estabilidade da função exercida, ou pelo conhecimento sobre o programa: diretor e supervisor estão em uma função com concurso próprio para este cargo. Já PCNP e PC realizam concurso para o quadro de professores 
e ocupam a função em que estão por terem participado de um processo seletivo interno da Diretoria de Ensino que não lhes garante a estabilidade e tampouco os mesmos direitos da função concursada - tal função pode cessar, levando-os a retornar à sala de aula a qualquer momento. Dessa forma, o poder ofertado pela função que exercem no processo formativo se enfraquece pela não estabilidade em relação aos demais atores da escola: diretor, supervisor e professor. Os sujeitos envolvidos na pesquisa, em seus discursos, apontam que diretores e supervisores muitas vezes não conhecem as diretrizes do programa. Contudo, os PCs acatam suas ordens pelo poder que possuem. Por outro lado, os formadores possuem poder pelo conhecimento que têm sobre o programa. Porque estes sujeitos têm mais tempo destinado à formação e por estarem envolvidos com os próprios formuladores do programa, suas prescrições são sempre vistas como determinantes ao trabalho dos PCs. A função do PC fica, então, nesse campo de tensão de poderes: ora atende às prescrições que recebe durante as formações, ora atende aos "chefes diretos": diretores e supervisores, os quais pouco se inserem na política do programa Ler e Escrever.

Os momentos de formação observados apresentaram pouco espaço para o debate e para o diálogo, mas foram repletos de prescrições sobre a prática, enfatizando sempre o como fazer. Não estamos aqui sugerindo que não possa haver discussões sobre as possibilidades de como desenvolver o trabalho pedagógico e tampouco compactuamos que o professor tenha de ter uma autonomia tal que todas as etapas do processo de ensino aprendizagem fiquem somente a seu critério. Entretanto, nossa crítica se insere na questão de apenas realizar prescrições como "faça assim". Defendemos esta crítica pelas argumentações que traremos a seguir.

Observamos nos documentos um discurso dividindo as concepções de alfabetização em dois grandes paradigmas - o tradicional e o novo. Segundo Lamy (2010), tais concepções estão fundamentadas em paradigmas que vão muito além da divisão entre tradicional e novo. Para a autora, há as concepções que privilegiam o sujeito e focalizam o desenvolvimento individual, a construção do sujeito e a representação de mundo (as concepções representacionais). As que privilegiam o processo de alfabetização priorizam as técnicas las concepções mecânicas). E, por fim, as que privilegiam o sujeito e o seu grupo social têm como central

[...] o desenvolvimento do indivíduo, tendo em vista um bem social. A alfabetização, assim, está a serviço, em função de, nas concepções funcionalistas. Serve de instrumento, meio de mudar radicalmente a sociedade nas concepções revolucionárias. Está a serviço do homem e da sociedade, tendo o social como um bem para o homem e não o homem como um bem para a sociedade, nas concepções conscientizadoras. (Lamy, 2010, p. 26 - grifos da autora) 
Encontramos nos documentos analisados uma polarização entre o velho e o novo paradigma. Entretanto esse "novo" pode se pautar por diferentes concepções, que não defendem a mesma coisa.

0 que identificamos nas observações foram repasses de práticas desejáveis pelos elaboradores do programa. Este repasse se dá pelo convencimento e pela vivência: modelo que não fundamenta, apenas imprime mudanças práticas.

Durante as observações realizadas foi possível identificar o discurso de que - PC possui "autonomia" para organizar as formações no interior da escola. Entretanto, na sequência, observamos um intenso processo de convencimento de práticas, lançando mão de expressões como: "vocês não acham importante trabalhar isso com o grupo de vocês?" Este discurso, então, aumenta a ênfase neotecnicista, ainda que não diretamente. Os discursos dos formadores apresentam marcas prescritivas ao trabalho formativo. Cargos estáveis podem realizar prescrições diretas, já os cargos instáveis exigem um convencimento, ou seja, grande uso de palavras convencedoras, revestidas de uma roupagem didática para serem aceitas.

Buscamos apontar neste trabalho a difícil possibilidade de se aplicar um modelo de formação que preze a formação dos PCs e PCNPs, em detrimento dos professores, pois os PCs e PCNPs possuem cerca de oito horas quinzenais para a formação e os professores possuem menos de duas horas semanais. Não bastasse a questão da carga horária como barreira para um processo formativo fundamentado, o modelo de repasse - a formação do PCNP é passada aos PCs, que por sua vez passam aos professores, que deveriam passar aos alunos, evidentemente, sem necessitar de grandes análises - aponta sérios problemas de funcionalidade. Obviamente este parágrafo sintetiza muito brevemente uma relação de formação que se estabelece de uma maneira sutil e cuidadosa na intenção de não ser imperativa, maquiada. Contudo, esta síntese permite-nos visualizar mais diretamente o processo estabelecido nessa rede formativa.

Um aspecto importante observado é que a maneira de os formadores, PCNP e $P C$, sentirem-se seguros de que o que estão trabalhando ou lendo corresponde à concepção do programa Ler e Escrever é citando autores que são explicitamente referenciados pelo programa, ou mesmo que fazem parte do programa, como Telma Weisz e Délia Lerner. A presença de livros com diferentes concepções é considerada pela formadora que observamos uma "saia justa", dando foco à fragilidade no posicionamento quanto às concepções e fundamentações do programa.

A valorização dada à estratégia dos seminários - atividade formativa utilizada pelo programa, em que um professor que possua uma prática considerada adequada realiza um seminário ensinando esta prática a outros professores - 
e a constatação, no material empírico, do uso constante da palavra "passar" nos confirmam uma tendência já identificada no discurso presente nos documentos oficiais: a tendência de valorização da prática e formação por meio da aprendizagem de práticas desejadas. Em nossa interpretação, estes aspectos mensuram uma nova retomada do tecnicismo pedagógico. Com o uso das expressões "será uma escolha de cada realidade", busca-se mascarar esta concepção que permeia a formação de que o professor irá "aprender fazendo" e de que as práticas ensinadas, em cada âmbito da formação, devem ser reproduzidas nas demais, formando, assim, uma rede de repetições de formações sem reflexão. Segundo Mira e Romanowski (2009, p. 1029), “a reprodução das relações de produção exige a reprodução das ideias que a suportam". Dessa forma, em cada âmbito são repassadas técnicas para serem aplicadas na prática do professor que, com a diminuição do tempo de formação, tendem a ser ainda menos refletidas e mais práticas, remetendo a um neotecnicismo. As autoras apontam também que o tecnicismo traz implícita a concepção positivista da ciência e a aprendizagem marcada pelo behaviorismo, compreendida como uma modificação de comportamento.

A partir da leitura de Saviani (2003), observamos o modelo tecnicista, contido no que o autor define como teoria não crítica; ou seja, não se busca uma mudança social, mas atender as necessidades da sociedade como ela se encontra. No caso do tecnicismo, a necessidade era produzir, tendo como elemento central a operacionalização racional dos meios, ou seja, saber fazer.

Segundo Mira e Romanowski, as críticas ao modelo tecnicista se baseavam em aspectos referentes à:

[...] elaboração dos procedimentos e objetivos pelos especialistas da educação; a desconsideração das diferenças de classe entre os estudantes, aliado à crença de que é possível compensar as deficiências; a inversão da avaliação e do próprio processo pedagógico, na medida em que as técnicas é que determinam os fins e só se ensina comportamentos que possam ser mensuráveis e que estejam previamente previstos no processo e, finalmente, o ocultamento das relações entre educação e sociedade. (Mira e Romanowski, 2009, p. 10212)

Não podemos considerar coincidências as semelhanças entre as críticas citadas acima e o processo formativo do programa Ler e Escrever. Na estrutura da formação, há um grupo "pensante" que é responsável pelo material e pela elaboração de formações. Essas formações se reproduzem nos demais âmbitos de formação, ainda que haja uma mensagem de que cada formador terá a autonomia para decidir se irá desenvolver aquela formação ou não. Percebemos, em nossas análises, o quanto é determinante o que é realizado nas formações. 
Outra semelhança é o ensino de comportamentos que possam ser mensuráveis. Observamos a grande influência que a avaliação em larga escala (Sistema de Avaliação do Rendimento Escolar do Estado de São Paulo - SARESP) exerce sobre as formações. E, finalmente, o ocultamento das relações entre educação e sociedade: questão que consideramos nodal. A literatura sobre o coordenador pedagógico não traz a reflexão sobre a relação entre a função deste e a função da escola e da sociedade. Este ocultamento, que é silenciado pelas técnicas, ora de leitura e escrita, ora de matemática, consideramos ser a questão central para organizar as formações no interior da escola.

Mira e Romanowski (2009), ao abordarem o neotecnicismo pedagógico, destacam que as questões empresariais, mais uma vez, caem sobre a escola, trazendo a eficiência, a competência e a qualidade total como questões centrais para o ensino. Tais aspectos permeiam as formações do programa Ler e Escrever que foram observadas, enfatizando a perspectiva de "passar" práticas desejáveis, que serão eficientes para que os alunos tenham um bom desempenho nas avaliações em larga escala e, dessa forma, fique assegurada a qualidade da escola. Este neotecnicismo, também segundo Mira e Romanowski (2009), se disfarça pelo uso da chamada "autonomia da escola" que, para elas, nada mais é do que a sobrecarga do diretor frente às questões administrativas - e aqui complementamos que também observamos a sobrecarga do professor coordenador, por meio da supervalorização do profissional, visando o aumento de índices de desempenho dos alunos, de forma que não fique possível a reflexão sobre a relação da escola com a sociedade.

Uma formação que visualiza os professores como reprodutores de técnicas pouco pode contribuir para um processo humanizador, e pode se relacionar a uma perspectiva reprodutivista e não crítica da educação, utilizando as definições de Saviani (2003). 0 que visualizamos em nossa interpretação se caracteriza num processo formativo que ajusta os sujeitos à sociedade capitalista que temos, a fim de que, no mínimo, leiam e escrevam para a demanda do mercado.

\section{Considerações finais}

Esta pesquisa buscou, então, problematizar a realidade da formação continuada no Estado de São Paulo, no âmbito do programa Ler e Escrever, que tem o professor coordenador como figura central no papel de formador de professores. Os procedimentos de análise do material empírico permitiram a identificação de resultados e considerações únicos e singulares à realidade observada que, entretanto, dialogam com aspectos gerais do programa. 
Considerando que um discurso nunca é neutro e que traz em si a polifonia de outros discursos, mesmo tendo observado uma única realidade formativa, tais discursos podem remeter aos discursos dos demais âmbitos que envolvem o programa Ler e Escrever. Os resultados apontam riscos, críticas e considerações que se relacionam àquela realidade única e singular, mas também, em alguns aspectos, se relacionam ao programa de uma forma global.

Identificamos uma iniciativa do Estado em ofertar formação continuada aos professores de sua rede. Queremos ressaltar aqui um aspecto importante que traz o programa Ler e Escrever, que é assumir a escola como lócus de formação. Defendemos, segundo a Teoria Histórico-Cultural e a Pedagogia Crítica, que a escola é um espaço originário de formação e que os espaços de reuniões entre coordenador e professor (ATPC) podem e devem ser assumidos como espaços de aprendizagem, ou seja, espaços formativos. Oferecer formações pode contemplar um processo que supere a alienação profissional, sendo um estímulo crítico à mudança, abrindo caminho para uma autonomia profissional compartilhada. A formação no interior da escola pode possibilitar ainda a articulação dos conhecimentos diretamente com a prática, promovendo transformações na realidade escolar. Consideramos importante uma preocupação do governo estadual com a formação e a consideração da escola como espaço de tal processo. Entretanto, em nossas análises encontramos aspectos que necessitam de reflexão.

Um aspecto que resultou da identificação da escola como espaço de formação continuada foi assumir o professor coordenador como formador de professores. Com isso temos o fortalecimento e uma especificação da função do coordenador. Vimos no levantamento bibliográfico realizado que a função do coordenador pedagógico encontra-se ainda em construção. O Estado de São Paulo, com a implantação do programa Ler e Escrever e as resoluções publicadas em 2007 (Resolução SE 86, 88 e 89), traz uma colaboração à delimitação da função, aproximando o coordenador das questões da sala de aula. 0 profissional que historicamente já tivera sua função mais ligada ao auxílio da direção recebe, então, um novo status.

As análises nos permitiram identificar que as formações do programa se dão numa espécie de rede de multiplicadores, em que há uma equipe de formuladores e uma equipe de formadores. Este processo tem uma positividade ao possibilitar que se ampliem, em termos quantitativos, as propostas e discussões da formação, pois alcança um número considerável de sujeitos no processo formativo. Entretanto, entraves foram identificados. Um entrave inicial é a questão do tempo destinado às formações nos diferentes âmbitos. Outros entraves foram analisados: as relações de poder que se dão neste processo 
e o modelo de formação encontrado pelas pesquisadoras, nos momentos de observação e entrevista.

Sobre as relações de poder que se estabelecem na formação, encontramos dois tipos de poder que perpassam essas relações: o poder pelo conhecimento que se possui sobre o programa e o poder ofertado pela estabilidade no cargo que se ocupa. Pela análise do material empírico, pudemos identificar a seguinte situação: supervisor, diretor e professor são figuras que ocupam cargos para os quais realizaram um concurso estadual para poderem exercer as suas funções. Isto thes configura uma estabilidade - exceto em casos graves, seu cargo e sua função estão assegurados pelo Estado. Já os PCNPs e PCs realizaram concurso para a função de professor e ocupam outra função ou por participarem de um processo seletivo próprio da Diretoria de Ensino, ou por receberem um convite para estarem nessa função. Entretanto, podem ser desligados e retornarem ao trabalho da sala de aula, por uma série de questões, que são descritas nas resoluções citadas. Os discursos que analisamos apontaram que diretor e supervisor, pela estabilidade de sua função, possuem um poder sobre o processo formativo. Mesmo que tenham sido apontados como aqueles que conhecem pouco do programa, suas palavras desempenham um poder de "cumpra-se". 0 professor, por sua vez, tem o poder de rejeitar propostas, de se posicionar, de apontar críticas e realiza essas ações com a confiança do poder de sua estabilidade. Esse aspecto nada teria de revelador, não fosse a condição de PC e PCNP não se encontrarem em igual posicionamento. Porque PC e PCNP são funções instáveis, os resultados apontaram a necessidade que se coloca de ambos atenderem às expectativas do diretor e do supervisor; ainda mais considerando que são ambos avaliadores do trabalho realizado, podendo mantê-los, ou não, nas referidas funções. Outro tipo de poder que encontramos situa-se nos formadores e configura-se pelo conhecimento que possuem sobre o programa. Sendo conhecedores das propostas, por vezes até formuladores delas, os formadores exercem diretamente sobre os PCs prescrições, que são recebidas com um peso de ordem. Essas ordens são mascaradas por expressões do tipo: "vocês não concordam que devem fazer isso com seu grupo?" "Vocês não consideram importante realizar esta atividade também com o grupo de vocês?" O poder dos formadores tende a se desencadear na rede de formações e o conteúdo de sua formação tem uma forte tendência de ser reproduzido nos demais âmbitos. Sendo assim, identificamos que as relações que ocorrem no processo formativo contribuem para um engessamento das práticas de formação - primeiro pelo poder e segundo pelo pouco embasamento teórico do PC. 0 trabalho do professor coordenador fica sob um campo de tensões e contradições nas divergências entre o poder do supervisor e o do diretor em relação ao poder 
dos formadores. Todos estes sujeitos convergem forças sob o trabalho do PC, que por sua vez encontra também o poder da equipe de professores, por vezes, em forma de resistência.

Nesta política de formação, podemos considerar que há um movimento de fortalecimento da função do professor coordenador. Os documentos que analisamos discorrem grandes expectativas ao trabalho desse profissional. A PC entrevistada aponta seu sentimento de importância na realidade escolar, especialmente ligado ao aumento de índices de desempenho nas avaliações, e vimos um direcionamento das formações privilegiando a formação do PC. Mesmo estando numa relação de poder marcada pela questão da estabilidade e não dispondo dessa estabilidade na função que está ocupando, a visão da PC sobre seu trabalho é carregada de importância e de valorização. Ainda que esteja nesse campo de tensões e perceba isso como uma dificuldade, a PC entrevistada identifica como necessárias as possibilidades do seu trabalho e acredita nele. Contudo, ainda que consideremos importante como essa política direciona a um fortalecimento e maior definição da função do professor coordenador, refletimos se não estão sendo lançadas expectativas demasiadamente ambiciosas para este profissional, especialmente considerando o pequeno tempo de que a PC dispõe para o trabalho com a formação dos professores. Ao determiná-la como - "novo agente da política de qualidade do Estado de São Paulo" (São Paulo, 2007c), corre-se o risco do desenvolvimento de uma política de responsabilização deste profissional, que pode tender a isentar o próprio Estado das suas responsabilidades em relação às condições para tal melhoria.

Nas observações dos momentos de formação, identificamos um direcionamento para a prática de sala de aula. É necessário considerar que durante muito tempo a queixa dos professores centrou-se em apontar que as formações que recebiam pouco se articulavam com as possibilidades da sala de aula e ficavam apenas no campo das teorias. Portanto, o foco prático foi uma necessidade levantada pelos próprios professores. Entretanto, o material que analisamos aponta para uma polarização nesse foco que pode trazer riscos e dificuldades para o trabalho formativo. Os discursos dos documentos oficiais (São Paulo, ca 2007; São Paulo, 2007a; 2007b; 2007c) apontam esta ênfase à mudança prática, tendo na figura do professor coordenador a responsabilidade por uma mudança, a qual foi fundamentada nos discursos por uma necessidade de mudança de paradigma. Apontamos, segundo Lamy (2010), que os paradigmas de leitura e escrita vão muito além da concepção de tradicional e novo. Nos discursos que analisamos nos documentos, nas entrevistas realizadas e nas observações feitas, a concepção de linguagem não fica clara. Desta forma, nossa reflexão é, se nem mesmo nos documentos e formações estão claras essas concepções, como este 
chamado novo paradigma conseguirá transformar fundamentalmente a prática dos professores?

O material empírico produzido permitiu impressões sobre o processo formativo que deixam as questões teóricas em segundo plano. Presenciamos uma proposta de formação calcada na vivência e repasse de atividades. Essa escolha traz um risco que pode prejudicar as próprias formações, pois valoriza a maneira de fazer e traz pouco embasamento sobre o por que fazer. Tal embasamento se faz por meio de matrizes teóricas, que, quando ausentes, tendem a configurar o professor como um aplicador de técnicas. 0 modelo de formação em rede, em que se multiplicam em vários âmbitos as formações vivenciadas, pode agudizar esta configuração. Pois uma vez que as formações tendem a ser repassadas em âmbitos com cada vez menos tempo para tal e se ocultam, ou não se assumem as concepções de qualidade, de paradigma, de linguagem, etc., com que propriedade chegarão essas formações aos alunos?

A vontade de se implantar um novo paradigma há que passar pelo estudo e busca de definição da concepção de linguagem que se defende. Uma vez que não há clareza nos próprios documentos nem durante as formações observadas, não se pode objetivar uma ação pedagógica fundamentada. 0 temor de que os docentes aceitem se tornar técnicos, que se contentem com o objetivo do seu trabalho em aumentar índices de desempenho dos alunos, permeia este trabalho. Tememos que aceitem técnicas prontas e que fiquem convencidos em levar essas técnicas para a sala de aula, apenas pelo fato de elas fazerem parte do sistema de avaliação. Tememos que os professores desacreditem em seu potencial crítico e transformador. Se esse potencial sozinho em meio à sociedade - focada no capital - já é tão pouco, como permanecer com esperança sem ele então?

\section{Referências}

ARCE, Alessandra. Compre um kit neoliberal para a educação e ganhe grátis os dez passos para se tornar um professor reflexivo. Educação e Sociedade. 2000.

BRASIL. Ministério de Educação e Cultura. LDB - Lei no 9394/96, de 20 de dezembro de 1996. Estabelece as diretrizes e bases da Educação Nacional. Brasília: MEC, 1996.

BRUNO, Eliane Bambini; CHRISTOV. Luíza Helena da Silva. Reuniões na escola: oportunidade de comunicação e saber. In: BRUNO, Eliane Bambini; ALMEIDA, Laurinda Ramalho; CHRISTOV, Luíza Helena da Silva (org). O Coordenador pedagógico e a formação docente. São Paulo: Edições Loyola, 2009. 
CHRISTOV, Luíza Helena da Silva. Educação continuada: função essencial do coordenador pedagógico. In: BRUNO, Eliane Bambini; ALMEIDA, Laurinda Ramalho; CHRISTOV, Luíza Helena da Silva (org). O Coordenador Pedagógico e a Educação Continuada. São Paulo: Edições Loyola, 2009.

DUARTE, Newton. Vigotski e o "Aprender a Aprender" Crítica às Apropriações Neoliberais e Pós-Modernas da teoria Vigotskiana. Campinas. Autores Associados, 2001.

FRANCO, Francisco Carlos. 0 coordenador pedagógico e o professor iniciante. In: BRUNO, Eliane Bambini; ALMEIDA, Laurinda Ramalho; CHRISTOV, Luíza Helena da Silva (org). O Coordenador pedagógico e a formação docente. São Paulo: Edições Loyola, 2009.

GATTI, Bernadete Angelina. A construção da pesquisa em educação no Brasil. Série: Pesquisa em Educação, vol. I. Brasília: Plano Editora, 2002.

GATTI, Bernadete Angelina. Análise das políticas públicas para formação continuada no Brasil, na última década. Revista Brasileira de Educação. v. 13. N 37. Jan/abril 2008.

GUIMARÃES, Ana Archangelo; VILLELA, Fábio Camargo Bandeira. 0 professorcoordenador e as atividades de início de ano. In: BRUNO, Eliane Bambini; ALMEIDA, Laurinda Ramalho; CHRISTOV, Luíza Helena da Silva lorgl. O Coordenador pedagógico e a formação docente. São Paulo: Edições Loyola, 2009.

LAMY, Gersolina Antônia de Avelar. Panorama da alfabetização no Brasil. In: LAMY, Gersolina Antônia de Avelar; HOELLER, Solange Aparecida de Oliveira (org.) Alfabetização em destaque. Campinas, Mercado de Letras, 2010.

MIRA, Marília Marques; ROMANIWSKI, Joana Paulin. Tecnicismo, neotecnicismo e as práticas pedagógicas no cotidiano escolar. Anais do XI Congresso Nacional de Educação. EDUCERE. 2009. Disponível em: <http://www.pucpr.br/eventos/ educere/educere2009/anais/pdf/2671_1108.pdf> Acesso em: 10 nov. 2013.

NÓVOA. Antonio. Formação de Professores e profissão docente. In: NÓVOA, A. (org.) Os professores e sua formação. Lisboa/Portugal: Publicações Dom Quixote, 1992.

NÓVOA. Antonio. Para uma formação de professores construída dentro da profissão. Revista de Educación. Ministério de Educación, Cultura y Desporte. Governo de España, no 350, septiembre-diciembre, 2009. Disponível em: <http://www. revistaeducacion.mec.es/re350/re350_09por.pdf.> Acesso em: 23 jun. 2014.

PIMENTA, Selma Garrido. 0 professor reflexivo: construindo uma prática. In: PIMENTA, Selma Garrido; GHEDIN, Evandro. (org.) Professor Reflexivo no Brasil gênese e crítica de um conceito. São Paulo, Cortez, 2002.

PLACCO, Vera Maria Nigro de Souza; SILVA, Sylvia Helena Sousa. A formação do professor: reflexões. Desafios, perspectivas. In: BRUNO, Eliane Bambini; 
ALMEIDA, Laurinda Ramalho; CHRISTOV, Luíza Helena da Silva (org). O Coordenador pedagógico e a formação docente. São Paulo: Edições Loyola, 2009.

PLACCO, Vera Maria Nigro de Souza; ALMEIDA, Laurinda Ramalho; SOUZA, Vera Lúcia Trevisan 0 Coordenador Pedagógico e a formação docente: intenções, tensões e contradições. Estudos e Pesquisa Educacionais. Fundação Victor Civita, 2011.

ROMAN, Marcelo Domingues. O professor coordenador pedagógico e o cotidiano escolar: um estudo de caso etnográfico. 2001. Dissertação (Mestrado em Psicologia Escolar e do Desenvolvimento Humanol - Instituto de Psicologia, Universidade de São Paulo, São Paulo, 2001. Disponível em: <http://www.teses.usp.br/teses/ disponiveis/47/47131/tde-08082006-150737/>. Acesso em: 2 ago. 2013.

SÃO PAULO (Estado). Secretaria de Estado da Educação. Política Educacional do Estado de São Paulo. Coordenadoria de Estudos e Normas Pedagógicas (CENP). $\mathrm{s} / \mathrm{d}$.

SÃO PAULO (Estado). Resolução SE - 86, de 19-12-2007. Institui, para o ano de 2008, o Programa "Ler e Escrever", no Ciclo I das Escolas Estaduais de Ensino Fundamental das Diretorias de Ensino da Coordenadoria de Ensino da Região Metropolitana da Grande São Paulo. São Paulo, 2007a. Disponível em: <http://siau. edunet.sp.gov.br/ItemLise/arquivos/86_07.HTM?Time=4/13/2013\%205:37:20\%20 PM>. Acesso em: 9 mar. 2012.

SÃo PAULO (Estado). Resolução SE - 88, de 19-12-2007. Dispõe sobre a função gratificada de Professor Coordenador. São Paulo, 2007b. Disponível em: <http:// siau.edunet.sp.gov.br/ItemLise/arquivos/88_07.HTM.> Acesso em: 9 mar. 2012.

SÃO PAULO (Estado). Resolução SE - 89, de 19-12-2007. Dispõe sobre a função gratificada de Professor Coordenador. São Paulo, 2007c. Disponível em: <http:// siau.edunet.sp.gov.br/ItemLise/arquivos/89_07.HTM?Time=4/13/2013\%20 5:43:12\%20PM.> Acesso em: 9 mar. 2012.

SAVIANI, Dermeval. Escola e Democracia: teorias da educação, curvatura da vara, onze teses sobre a educação política. Campinas, SP. Autores Associados, 2003.

SCHÖN, Donald. Formar professores como profissionais reflexivos. In: NÓVOA, A. (org.) Os professores e sua formação. Lisboa/Portugal: Publicações Dom Quixote, 1992.

VIGOTSKI, Lev Semenovitch. Obras Escogidas. Problemas del desarrollo de la psique. Vol III. Madrid: Visor, 1995.

Recebido em março de 2014

Aprovado em agosto de 2014 
Camila dos Santos Almeida é mestre em Educação pela Pontifícia Universidade Católica de Campinas e integrante do grupo de pesquisa Formação e Trabalho Docente. Bolsista da Fundação de Amparo à Pesquisa do estado de São Paulo (FAPESP), no período de 2012-2014. E-mail: mila.85aig.com.br

Elvira Cristina Martins Tassoni é doutora em Educação pela Universidade Estadual de Campinas (Unicamp) e professora do Programa de Pós-Graduação em Educação da Pontifícia Universidade Católica de Campinas. Integrante do grupo de pesquisa Formação e Trabalho Docente. E-mail: cristinatassoniđauccampinas.edu.br 